\title{
PRACTICE
}

\section{BUILDing Equity in STEM: A Collaborative Undergraduate Research Program to Increase Achievement of Underserved Community College Students}

\author{
Jared Ashcroft, Veronica Jaramillo, Jillian Blatti, Pasadena City College \\ Shu-Sha Angie Guan, Amber Bui, Veronica Villasenor, California State University, Northridge \\ Alina Adamian, Gabriela Chavira, Carrie Saetermoe, California State University, Northridge \\ Eileen le, Bryant Horowitz, Brissa Palacios, East Los Angeles College \\ Pamela Byrd Williams, Erika Brockman, Los Angeles Valley College \\ Jennifer Moses, Los Angeles Pierce College
}

\begin{abstract}
Undergraduate research programs at community colleges maximize their impact through partnerships with baccalaureate-granting institutions, which provide much needed access to subject matter experts, research labs, and funding to underserved students. The program Building Infrastructure Leading to Diversity: Promoting Opportunities for Diversity in Education and Research (BUILD PODER) partners baccalaureate-granting California State University, Northridge with community college faculty and students to facilitate undergraduate research and development at community colleges. Eighty-one community college students and 41 community college faculty mentors have participated in BUILD PODER, performing research in STEM and biomedical disciplines. The authors document student, faculty, and institutional outcomes as well as share best practices in forming community college-university partnerships. Future directions also are offered in the development and implementation of transdisciplinary, multiinstitutional community college collaborations.
\end{abstract}

Keywords: community college partnerships, equity, faculty mentoring, interdisciplinary undergraduate research

doi: $10.18833 /$ spur/4/3/11

Data compiled by the Community College Research Center (CCRC) show that 49 percent of students who have completed baccalaureate degrees enrolled in a community college at some point in their educational career (CCRC
2020). Moreover, 49 percent of Black students and 51 percent of Hispanic students started their collegiate career at a community college, compared to 36 percent of white students. With increasing career opportunities in science, technology, engineering, and mathematics (STEM) fields, many adult learners enroll in community colleges to further their education in the sciences (Chen 2019). It has been shown that undergraduate research is an educational practice that maximizes the impact of a postsecondary education early in a student's academic career (Bowman and Holmes 2018), particularly with Black, Indigenous, and people of color (BIPOC) student populations. Specifically, undergraduate research has been shown to cultivate self-efficacy and career ambitions in BIPOC students (Carpi et al. 2016). Given that nearly half of postsecondary students begin their academic education at community college, where the student population is largely composed of BIPOC students who benefit the most from research experience, it is imperative that community colleges provide undergraduate research opportunities.

Providing a comprehensive research experience at a community college is challenging for a variety of reasons (Cejda and Hensel 2009). Limited financial resources and lab space, extensive teaching loads, disengaged faculty and students, the lack of connection to research networks, the experience of feeling marginalized in the science research experience, and insufficient administrative support make the pursuit of a community college undergraduate research program appear insurmountable (Hewlett 2018). Through active engagement with university partners, however, 
TABLE 1. Enrollment and Transfer Data for BUILD PODER Community Colleges

\begin{tabular}{|l|c|c|c|}
\hline College & Enrollment & Percent BIPOC & Overall transfer \\
\hline ELAC & 60,146 & $71 \%$ & $5 \%$ \\
\hline LAPC & 28,876 & $53 \%$ & $9 \%$ \\
\hline LAVC & 26,975 & $57 \%$ & $10 \%$ \\
\hline PCC & 40,372 & $54 \%$ & $8 \%$ \\
\hline
\end{tabular}

Note: Overall transfer data obtained for student cohort beginning spring 2017 and transferred by summer 2019 $($ CCCCO n.d., 2020). ELAC $=$ East Los Angeles College; LAPC $=$ Los Angeles Pierce College; LAVC $=$ Los Angeles Valley College; PCC $=$ Pasadena City College. BIPOC $=$ Black, Indigenous, and people of color.

community colleges can overcome these obstacles and create a transdisciplinary undergraduate experience that will change students' perceptions of science education and allow them to develop a research identity. In addition to creating an opportunity for community college students to gain meaningful research experience, these partnerships also help community college faculty grow as educators as they become research mentors to students who desire their support in STEM.

Multi-institutional, course-based research partnerships do exist. For example, the Genomics Education Partnership (Reeves et al. 2016) and Science Education AlliancePhage Hunters Advancing Genomics and Evolutionary Science (Laungani et al. 2018) each provide professional development and curriculum in genomics for community college STEM faculty. These collaborative opportunities offer a mechanism to expand involvement of community college students in undergraduate research but lack the ability to sustain research over time and become institutionalized, a necessary component in optimizing the success of research experiences (Hernandez et al. 2018). Establishing faculty-driven community college research programs that partner with research universities provides a scalable and sustainable platform for longitudinal undergraduate research projects to maximize the success of BIPOC students in STEM.

\section{BUILD PODER: A Model Research Partnership}

Federal agencies such as the National Institutes of Health (NIH) and the National Science Foundation (NSF) recognize the importance of representation and diversity in STEM and are committed to supporting BIPOC scientists through sustainable opportunities (NSF 2016; Valantine, Lund, and Gammie 2016). In 2014, the NIH launched the Building Infrastructure Leading to Diversity (BUILD) initiative aimed at implementing evidence-based practices in the research education of BIPOC students as well as facilitating faculty development and enhancing institutional research infrastructure. The BUILD program encourages partnerships between community colleges and baccalaureate-granting institutions to enrich research activities and expand the pool of engaged, underrepresented graduate students. The BUILD PODER (Promoting Opportunities for Diversity in Education and Research) program at California State University, Northridge (CSUN) is part of a 10-campus national consortium dedicated to making a broad impact by enhancing the diversity of the STEM workforce through community and educational partnerships. The goal is to increase students' interest in biomedical research to nurture their interest in pursuing research careers.

To promote interdisciplinary perspectives and support underfunded community college research programs seeking to recruit talent at inflection points in BIPOC student trajectories, BUILD PODER partnered with four California community colleges, as highlighted in Table 1: East Los Angeles College (ELAC), Los Angeles Valley College (LAVC), Los Angeles Pierce College (LAPC), and Pasadena City College (PCC).

In alignment with the BUILD program's mission to enhance diversity and equity in STEM, these community college partners are all minority-serving (MSI) and Hispanic-serving institutions (HSI). Faculty and students at each campus participate in mentoring activities that focus on providing equity in education and building research skills. Community college faculty mentors further their students' research knowledge while providing opportunities to view their STEM journey through the lens of critical race theory over the one-year research program. At the conclusion of the BUILD PODER-funded community college research, students can choose to transfer to CSUN and continue their research training, funded by NIH BUILD for two additional years. The early introduction of students to multifaceted, interdisciplinary research and progression to a university lab upon transfer are unique opportunities for community college students that increase engagement and promote continuity in their research endeavors, as shown in Figure 1. One student commented:

I gained confidence as a scientist, felt more certain while conducting research in lab, and learned more 
FIGURE 1. Students Participate in All Facets of Research
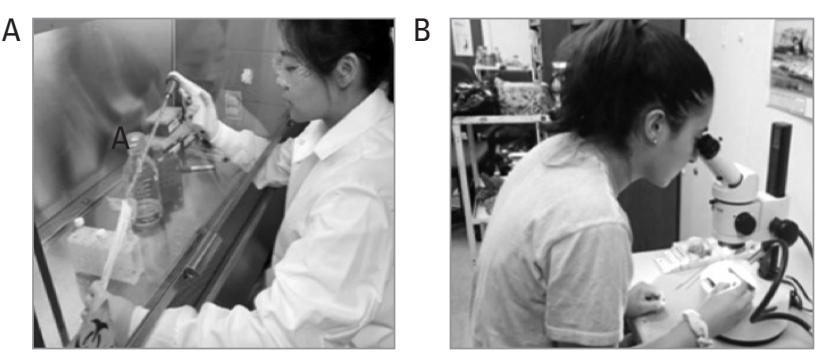

(A) Christine Lee performing biological assays at Oak Crest Institute of Science;

(B) Alina Shahin using a microscope at Pasadena City College

about graduate schools. The pipeline between CSUN and LAVC also offered me a support system once I transferred to CSUN. Being an undergraduate researcher made my transition from a community college to a university easy, helped me learn about myself, and awarded me with friendships that will last a lifetime.

\section{BUILD PODER: Critical Race Theory and Program Components}

The BUILD PODER program is unique among other BUILD programs in that its foundation in critical race theory (CRT) encourages participants and institutions to assess and address systemic and institutional factors that influence students' science-related educational decisions. CRT in education has five basic assumptions, as follows: (1) race and racism are central and defining characteristics of US society and embedded in structures such as universities; (2) dominant ideologies such as university objectivity, meritocracy, and race neutrality should be challenged; (3) a social justice agenda is critical to eliminating inequality; (4) experiential knowledge of people of color is a legitimate and critical resource central to understanding inequalities and solutions; and (5) historical contexts and interdisciplinary perspectives are necessary for analyzing race and racism in larger systems (Solórzano, Villalpando, and Oseguera 2005). CRT is infused into BUILD PODER objectives and program activities (Saetermoe et al. 2017). The inclusion of community colleges in BUILD PODER advances the CRT component in that the majority of student and faculty participants have BIPOC demographics.

\section{Selection Criteria}

Prior to the BUILD PODER program, students may not have been expected to have a commitment to a research career, since few may have considered research as a career option. Through participation in BUILD activities, students develop interest in research activities, graduate school, and pursuit of research careers. BUILD PODER community college students are selected for the program using the following inclusionary criteria: (1) being a current student at one of the four partner campuses; (2) having full-time enrollment status; (3) having a STEM field major relevant to biomedical science (e.g., biology, psychology, or public health); (4) having a 3.0 or higher grade point average; (5) being a US citizen or noncitizen national or permanent resident; (6) being Black, Indigenous, or a person of color or having a disability or disadvantage; and (7) having completed at least 30 units of undergraduate-level courses and having a one-year commitment to the program.

\section{Summer JumpStart}

New BUILD PODER students are funded to participate in a four-week Summer JumpStart (SJS) program that focuses on team-building exercises, research skills development, exposure to ethical considerations in research with human subjects, and exploration of the mentor-mentee relationship. SJS activities increase students' sense of community, research abilities, and program expectations. Students also are introduced to CRT and develop strategies for challenging and countering microaggressions and stereotype threat in academia. SJS commences at CSUN and continues with online meetings that occur bimonthly over the course of the academic year. Community college students are afforded student housing at CSUN for the four-week SJS session, which increases engagement and promotes interactions with students and faculty at the host institution.

\section{Mentorship and Support System}

The organization of BUILD PODER at each community college includes one faculty liaison who assists the respective institution's financial expert and BUILD PODER recruitment specialists. Together, these team members organize efforts to publicize and promote program initiatives, help establish student tutoring, address questions from mentors and trainees, and report on updates and common concerns at strategic meetings with the program's administrative team. Community college liaisons work with program specialists at CSUN to coordinate crossinstitutional meetings, organize recruitment workshops, and track student progress.

Given the CRT emphasis, faculty mentors are exposed to historical and structural perspectives about race during mentor training before working with mentees. Students and faculty collaborate on a defined biomedical research project. They are given a stipend and research funds to engage in projects that leverage science to address health disparities. Additionally, they have access to conference travel funds to collaboratively engage with researchers in the scientific community. All program participants and the university community are invited to talks and workshops led by speakers from diverse backgrounds who specialize in biomedical research. Additionally, community college faculty mentors use current events to open CRT-based discussions on equity, inclusion, and diversity in STEM. For example, they might discuss the 
impact of the political landscape and the Black Lives Matters movement on racial disparity as related to the mental health and well-being of BIPOC groups, with a specific focus on effects in STEM education.

\section{Summer Internships}

Performing undergraduate research at a community college provides students the opportunity to submit a more substantial application for a career-enhancing summer undergraduate research internship. Unfortunately, many of these internship programs select students from elite universities who have shown a history of research participation, making it difficult for community college students to be competitive for inclusion in these experiences. To remove this barrier, the BUILD PODER partnership includes negotiated or supplemental spots in many of these summer undergraduate research internships for participants who choose to continue the program at CSUN. Although community colleges are ideal for the initial development of students' research identity, summer internships in highly regarded research labs allow students to independently flourish and develop deeper professional networks. During summer 2019, 43 of the 81 BUILD PODER community college students participated in paid summer undergraduate research internships.

\section{Conference Presentations}

Effective undergraduate research experiences should encourage students to attend and present their research findings at conferences and, if warranted, publish their work. These opportunities can be transformative experiences for students, many of whom have never traveled out of their home states. Attending a national conference, even without doing a presentation, allows students to learn networking skills and increases their knowledge of current research being performed in their fields of study. Presenting at a conference is an especially beneficial practice for new researchers. Typically, every aspect of a research study must be complete to present work at a conference. This often is not feasible for undergraduate research students, especially at a community college where faculty advisers are challenged by the constant carousel of participating students. It is difficult for students to generate the data needed for project completion in the short time they are at a community college. Furthermore, it is unreasonable to expect students who are taking four or more courses and typically have external employment and familial obligations to have 20 hours per week available to complete a research project. It is much more likely that community college students have only four to five hours of time per week to work on research, which may not overlap with faculty availability. To address this obstacle, one strategy is to form student project cohorts, which consist of one student leading three to four other students on a project and allow for more widespread research. These cohorts maximize engagement by encouraging students to take the lead on projects and by providing research dissemination opportunities that are resume builders. The major benefits of the BUILD PODER-community college partnership are that students can form cohorts within a community college research structure, present at an end-of-year conference at CSUN, and receive travel scholarships to present at a conference of their choice. Over the first five years of this partnership, all 81 students have presented at regional or national conferences, and 27 community college undergraduate research students have been published in 12 peerreviewed publications.

\section{Curriculum Development}

Formal curricula have been established through BUILD PODER community college partners to complement research and introduce social justice in STEM education and health to a broader audience. A Public Health for Social Justice course was created at PCC, LAVC, and ELAC, which introduces health disparities research and the role of biomedical research in generating health equity. The LAVC course Public Health, Social Justice, and Biomedical Research is an independent study umbrella course within the biology program. This course incorporates speakers from public health departments who speak on social and public health matters within the community. University researchers and scientists, as well as graduate students, discuss research topics and introduce scientific research as a career pathway. The course also incorporates field trips that showcase urban plight, fewer grocery stores, and other societal disparities.

\section{BUILD PODER: Community College Student Impact}

Data regarding the race or ethnicity of students who transfer to baccalaureate-granting colleges and universities in specific STEM fields are challenging to obtain. However, all community college BUILD PODER students who transferred to CSUN earned associate's degrees (e.g., AA-Transfer, AA-Natural Science) from their community college before transferring. Therefore, the graduation rates for BUILD PODER students can be compared to that of BIPOC students at the partnering campuses, where overall graduation rates are considerably less than 40 percent (see Table 2).

As seen in Table 3, 81 community college students have participated in the BUILD PODER partnership program. Thirteen out of the 16 community college students from cohort 1 transferred to CSUN to continue in BUILD PODER. In total, 14 students (87.5 percent) graduated with a bachelor's degree. This is higher than the overall five-year graduation rates for CSUN first-time transfer students from the same cohort (2015-2016) from institutions representing biomedical fields such as schools of social and behavioral sciences ( 82.8 percent), health and human development (81.4 percent), engineering and computer science (64.9 percent), and science and math 
TABLE 2. BUILD PODER Community College Graduation Rates by Race/Ethnicity

\begin{tabular}{|l|l|l|l|l|}
\hline Race/ethnicity & ELAC & LAPC & LAVC & PCC \\
\hline Asian & $52 \%$ & $37 \%$ & $45 \%$ & $55 \%$ \\
\hline Black & $46 \%$ & $19 \%$ & $13 \%$ & $18 \%$ \\
\hline Latinx & $28 \%$ & $29 \%$ & $22 \%$ & $25 \%$ \\
\hline White & $88 \%$ & $39 \%$ & $36 \%$ & $48 \%$ \\
\hline Avg. grad. rate & $35 \%$ & $32 \%$ & $27 \%$ & $37 \%$ \\
\hline
\end{tabular}

Note $:$ ELAC = East Los Angeles College; LAPC = Los Angeles Pierce College; LAVC = Los Angeles Valley College; $\mathrm{PCC}=$ Pasadena City College

TABLE 3. Yearly Outcomes and Completions for BUILD PODER's Community College Students

\begin{tabular}{|l|c|c|c|c|c|}
\hline Year & $\begin{array}{c}\text { Total BP } \\
\text { students }\end{array}$ & $\begin{array}{c}\text { Transfer } \\
\text { CSUN-BP }\end{array}$ & $\begin{array}{c}\text { Transfer to } \\
\text { other university }\end{array}$ & $\begin{array}{c}\text { Graduated } \\
\text { with BA/BS }\end{array}$ & $\begin{array}{c}\text { Graduate } \\
\text { school }\end{array}$ \\
\hline $2015-2016$ & 16 & 13 & 2 & 14 & 9 \\
\hline $2016-2017$ & 15 & 8 & 5 & 6 & 2 \\
\hline $2017-2018$ & 19 & 6 & 10 & N/A & N/A \\
\hline $2018-2019$ & 23 & 5 & 15 & N/A & N/A \\
\hline $2019-2020$ & 8 & 6 & 2 & 6 \\
\hline
\end{tabular}

Note $:$ CSUN = California State University, Northridge; BP = BUILD PODER. Average time to completion at a baccalaureate-granting institution was three years after transfer.

(75.3 percent), particularly for BIPOC students (77.1, 80.1, 57.6, and 74.1 percent, respectively). Furthermore, 9 students (56 percent) from that initial cohort enrolled in graduate school. Across all five years, only 9 students (11 percent) have not graduated or are no longer enrolled in a community college or university. The average time to completion at a baccalaureate-granting institution after transfer is three years. Therefore, only the first and second cohorts of students have had sufficient time to complete their degrees and apply for graduate school. The BUILD PODER research program increased the desire of many students to obtain doctoral degrees, as demonstrated by student narratives such as, "I moved from probably wanting to get a graduate degree to knowing I wanted to earn a Ph.D. in order to research the questions that I want to answer."

BUILD PODER students share their experiences about the program and what they are doing via outreach and presentations to other students. This has proven to be an effective strategy for encouraging other students to pursue research experiences, otherwise known as "the BUILD effect." What follows are some categories of benefits reported by students due to BUILD PODER opportunities:

1. Gaining lab experience. Research opportunities, taking place in local summer internships, allow for increased competency in laboratory skills within a research setting, which is essential to development of a science identity:

During the first Summer JumpStart training we learned about what research is and I got to work in a lab with real equipment and live cells. It was straight out of a movie and I had never thought I could do that. My perception of a scientist was the complete opposite of who I am. . . . During my year at LAVC I was able to build my confidence and improve on my grades/study skills and learn some of the foundational lab skills which have shaped the scientist I am today.

2. Applying academic skills to real-world settings. Research opportunities facilitate students' ability to design research questions that have real-life applications that are, if possible, tailored to each student's interests:

I studied the impact of chemicals such as heavy metal nitrates and nanoparticles on plant growth and development. This project taught me valuable research skills such as how to operate scanning electron microscopes (SEMs), construct posters, and communicate scientific research at conferences. The results of this experiment emphasized the importance of preventing contamination of soils by industrial contaminants. 
3. Learning the research process. Through research opportunities, students can apply the scientific method and build their critical thinking skills, inspiring them to become lifelong learners: "I enjoyed all of the time I spent both working in the lab and reading background literature, and I slowly began to realize that I never wanted to stop learning biology."

4. Building networking and support systems. Summer research and conference presentations provide opportunities to meet with scientists and industry leaders to discuss future academic and career directions and guide students on their academic path:

The pipeline between CSUN and LAVC offered me a support system once I transferred to CSUN. I did not feel alone while at CSUN, and I always felt as if I had someone that I would be able to turn to if I had questions about anything. Being an undergraduate researcher made my transition from a community college to a university easy, helped me learn about myself, and awarded me with friendships that will last a lifetime.

This support system may be especially powerful for BIPOC students:

As a first-generation college student, I had limited role models that could guide me towards an academic route. As a result, being a part of the mentorship program positively influenced my outlook on mentoring because it helped me combat the imposter syndromefeelings I encountered during my first year in college, such as not feeling good enough.

5. Developing collaboration skills. External summer research opportunities in particular encourage and foster a collaborative environment in which fellow interns, graduate students, and postdoctoral fellows work on a common project. Students recognize that mentorship is an interdependent, two-way relationship that results from collaboration:

Collaborating with a community college faculty mentor enriched my undergraduate experience. Working alongside my faculty mentor encouraged me to become academically driven and explore graduate programs, something I did not consider before. Learning about my mentor's academic experience also helped shape my view on mentoring because it provided me with a framework on how to approach my educational path.

6. Preparing future professionals. Summer research facilitates a discussion of the STEM education pursuit and disseminates shared knowledge of how to become a professional scientist, which is an effective motivator for community college students. Students reported that they were more informed and "learned more about graduate schools," confiding that research mentorship was "the biggest influence on my career path."

Community college students in BUILD PODER obtained skills, confidence, mentorship about professional choices, and tangible outcomes. Such outcomes included presenting at conferences; receiving support when applying to baccalaureate research institutions and graduate schools; and networking with a community of scholars, instructors, and students, all of whom inspire students who have traditionally been discouraged to believe that their work can generate social justice through health equity research.

\section{Other Programs: eCURE-BUILD PODER Model}

Prior to partnering with CSUN and BUILD PODER, PCC developed a distinct undergraduate research program to provide research experience for BIPOC students early on their STEM career pathway. The Early Career Undergraduate Research Experience (eCURE) utilizes a tiered research approach: (a) course-based undergraduate research experiences, (b) faculty-mentored research, and (c) summer internships (Ashcroft, Jaramillo, and Blatti 2020). Many students that begin with eCURE apply to BUILD PODER. Two aspects of eCURE that most benefited participants were the development of one-semester research method courses at PCC and additional internship partnerships with California State Polytechnic University, Pomona; Oak Crest Institute of Science; the Jet Propulsion Laboratory; and Huntington Medical Research Institute.

A total of 37 students, several of whom eventually participated in BUILD PODER, enrolled in three research methods courses at PCC. These courses included a biological research methods course - which had 7 students - and two physical science research methods courses that had 12 and 18 students, respectively. Presurveys and postsurveys were given to students (24 students completed both) to ascertain their experiences with four components of research:

1. Relationship of research. Does research address realworld problems? Does research relate to STEM coursework?

2. Understanding of research. Does research connect key ideas with other knowledge? Can research students apply what they learn to other situations?

3. Research skills. Can students critically read STEM articles, identify patterns in data, develop an argument for a research topic, recognize strong evidence, present data in presentations and in papers, and work well with others when performing research?

4. Attitudes toward research. Are students understanding research concepts, confident in applying research methods, interested in discussing research, willing to ask instructors for help, planning to participate in internships, and enthusiastic about research? 
TABLE 4. Presurvey and Postsurvey Comparisons of Students' Self-Reflection on Research Gains after Research Methods Course

\begin{tabular}{|l|c|c|c|c|c|c|}
\hline & & & \multicolumn{2}{|c|}{ Wilcoxon signed rank test } \\
\cline { 4 - 7 } & Pre (SD) & Post (SD) & Change & $N$ & $Z$ & $P$ \\
\hline $\begin{array}{l}\text { Relationship of } \\
\text { research }\end{array}$ & $8.3(1.4)$ & $8.6(1.3)$ & $4.0 \%$ & 23 & 1.078 & 0.281 \\
\hline $\begin{array}{l}\text { Understanding of } \\
\text { research }\end{array}$ & $7.7(1.7)$ & $8.6(1.6)$ & $11.7 \%$ & $\mathbf{2 3}$ & $\mathbf{2 . 1 2 3}$ & $\mathbf{0 . 0 3 4}$ \\
\hline Research skills & $28.0(7.0)$ & $32.7(5.6)$ & $16.6 \%$ & $\mathbf{2 4}$ & $\mathbf{3 . 2 1 4}$ & $\mathbf{0 . 0 0 1}$ \\
\hline $\begin{array}{l}\text { Attitudes toward } \\
\text { research }\end{array}$ & $33.0(5.5)$ & $34.5(4.9)$ & $4.7 \%$ & 24 & 1.814 & 0.070 \\
\hline
\end{tabular}

Note: Boldface signifies statistically significant data.

Analysis of survey data based on student self-reflection is shown in Table 4. Survey data have been shown to be an acceptable method of evaluation (Morales-Doyle 2017). Two components of the research process, understanding of research and research skills, both showed statistically significant improvement based on a Wilcoxon signed rank test after the research methods course. The Wilcoxon signed rank test is a nonparametric statistical hypothesis test used to compare two related samples-in this case, the presurvey and postsurvey results for each of the research gains. Relationship of the factors "Research" and "Attitudes toward Research" also showed improvement, although the changes were not statistically significant. This demonstrates that the research methods courses strengthened students' knowledge of research and connection of research to real life. These aspects of research are more challenging to simulate in a classroom setting.

\section{BUILD PODER: Community College Faculty and Staff Perspective}

Community college faculty, staff, and CSUN recruitment specialists were invited to share their personal assessment of the BUILD community college partnership program by reflecting on the following:

1. Successes. What do you view as successes of the BUILD Partnership? What strategies were instrumental in developing these successes?

2. Challenges. What do you view as challenges in the BUILD partnership? What strategies might be used to address them in the future?

3. Recommendations. Overall, what are your recommendations for individuals hoping to build cross-institutional partnerships?

Categories and themes from six personal reflections were constructed from open and axially coded data (Corbin and Strauss 1990). The personal narratives afforded insights on participants' attitudes, beliefs, and actions. Related to successes, three themes emerged: student empowerment, faculty interdisciplinary productivity, and benefits of community college strengths. Regarding challenges, two broad themes emerged: challenging ideologies about science and need for institutional support. Recommendations will conclude this section.

\section{Successes}

Student empowerment. Given the emphasis on student success of the undergraduate research program, faculty and staff focused on how the program empowers students. Specifically, community college faculty mentors noted student improvement in the ability to critically review literature, collect and analyze data, and prepare and deliver presentations. Additionally, students developed confidence and organizational skills that prepare them for transfer to a university. These research and academic gains can be attributed to applied research experience and psychosocial factors related to the expanded relationships gained through faculty mentorship at a community college (Villasenor et al. in preparation). Community college students tend to have a "commuter school mentality," and many entry-level STEM courses (such as chemistry) can feel like gateway classes meant to weed out students. By providing research experiences and opportunities to discuss socio-scientific issues through CRT with faculty-facilitated peer support groups, students are provided with encouragement, helping them through critical junctures experienced by all undergraduate students. This is particularly true for students whose family or friends are unable to provide such support. Through partnerships such as BUILD PODER, these supportive community networks empower students to succeed.

Faculty interdisciplinary productivity. Among faculty, the partnership has increased interdisciplinary research and productivity. As part of the BUILD PODER program, community college faculty can apply for sponsored projects. These sponsored projects (shown in Table 5) include participation in a summer writing group, research exchanges and pilot studies, equipment grants, and skillsbuilding workshops. In some instances, equipment such as fluorescent and optical microscopes as well as augmented 
TABLE 5. Collaborative Community College Projects Supported by the BUILD PODER Partnership

\begin{tabular}{|l|l|l|}
\hline Collaborative community college project & \multicolumn{1}{|c|}{ BP activities } & \multicolumn{1}{|c|}{ Outcomes } \\
\hline $\begin{array}{l}\text { Success of CSUN and Community College Education in } \\
\text { Science Study (SuCCESS) }\end{array}$ & Skills-building workshops & In-preparation manuscripts \\
\hline NSF Bridges to the Baccalaureate & Research funds & $\begin{array}{l}\text { Submitted CSUN-Community } \\
\text { College pipeline grant }\end{array}$ \\
\hline Virtual/augmented reality simulation lab & Research exchange & VR/AR lab and project \\
\hline NSF grant: Micro Nano Technology Education Center & Writing group & NSF grant awarded \\
\hline $\begin{array}{l}\text { Evaluation and research on utilization of targeted } \\
\text { nanoparticles for use as cancer therapies pilot }\end{array}$ & Pilot project & NIH grant in final review \\
\hline Informal science learning microscope laboratory & Equipment grant & Fluorescent and optical microscope lab \\
\hline
\end{tabular}

Note $:$ CSUN = California State University, Northridge; BP = BUILD PODER; VR = Virtual Reality; AR = Augmented Reality

and virtual reality devices were supplied for community college research programs. Access to subject matter experts at CSUN through the sponsored projects enhanced research capabilities at the community colleges. In addition, through the BUILD PODER partnership community college faculty can seek out opportunities to share research and to be compensated for the additional work. BUILD PODER also has made inroads in seeking administrative support, which is crucial to faculty retention and program sustainability. Partnerships with research universities allow faculty at the community college to develop relationships and increase scientific research capacity, which helps build competitive resumes for grant applications. For example, PCC applied for and was awarded an NSF Advanced Technological Education pilot grant specifically for the eCURE program. By leveraging this partnership experience, community colleges can obtain funding to support and expand their research programs, which in turn will support and provide students with opportunities not previously offered.

Benefits of community college strengths. The community college environment is viewed as a strength and potentially more conducive to BIPOC student development than traditional research institutions. The greatest success of the BUILD community college partnership was the development of one-on-one research mentorships for students in a formative environment. One student commented: "My mentors really pushed research. I am glad they did. BUILD gave me access to key mentors through community college and made for an easier transfer to CSUN. Now having mentors that have helped me build a strong foundation in education and research, I feel confident that I will succeed in a career in science." Research labs can often be competitive and summative in nature, rather than cooperative and formative. University research institutions are hypercompetitive for faculty, and such a situation can be conveyed to students. This can become a fraught environment in which students are concerned with self-presentation rather than research exploration, and the inherent mistakes are costly.

In a CRT framework, community college mentors are key to the outreach and support of students who have little exposure to research and role models who look like them. Challenging racist stereotypes by speaking openly about racism, recognizing the power of research to build social justice, holding high expectations, and providing essential mentoring allows educators to draw upon a much broader, more diverse pool of students who are inspired to solve the problems they see around them (Jain, Melendez, and Herrera 2020; Ledesma and Calderon 2015). Critical mentoring allows students to overcome stereotype threat and believe that they can contribute to their families, their communities, and their society (Steele, Spencer, and Aronson 2002). Community college research experiences can provide an environment that supports students' science identity in the safety of a scaffolded environment where mistakes are opportunities for growth. A student commented: "Through BUILD PODER, the lessons I was given in the classroom were no longer just limited to a test but transcended to my initial research experience at LAVC and the rest to come. BUILD has imbued me with the confidence and identity needed to pursue a career of science."

\section{Challenges}

Science ideology. Program recruitment specialists reported that students' beliefs about the relevance of research to their daily lives was a major challenge to recruitment. In addition to challenging the "gateway mentality" of science faculty, the competitive culture of science, and the community college emphasis on transfer, the BUILD recruitment specialists outlined how students who met the minimum requirements for the program then had to be informed about what research entails and how it could be leveraged for social justice. For many students, especially BIPOC, the word research was pushed aside since they believed it did not apply to them or was an unreachable 
goal. The presence of multi-institutional partnerships such as BUILD PODER at community colleges has enriched the university experiences of BUILD and non-BUILD students by shifting mind-sets and motivating them to seek research opportunities that are integrated into their everyday lives and social justice goals.

Cultural expectations at different levels can hinder BIPOC student participation in science at community colleges and, hence, research. On the individual level, students may not associate their interest or major with science. For example, many BIPOC female students in nursing may associate with the allied health field but not necessarily view themselves as STEM students or in a "science research" field. In addition, BIPOC students from families with expectations that the students will provide financial support make juggling education and expected employment difficult to manage. Students feel the pressure from two directions: education and familial obligation (Vasquez-Salgado, Greenfield, and Burgos-Cienfuegos 2015). These obligations inhibit participation in a research program.

On an institutional level, community college culture emphasizes employment and transfer rather than development of a science identity and research (Jain, Melendez, and Herrera, 2020). Therefore, community college students may prioritize coursework and getting an A in class over participating in research programs or internships, which are deemed unimportant. The presence of multiinstitutional partnerships, including BUILD PODER, at community colleges has helped enrich students, provided financial support for students, and served as a motivator for other students in seeking out research opportunities.

Institutional support. Across faculty, concerns about infrastructure and delay were common and highlighted the need for administrative support and recognition for efforts above and beyond heavy teaching loads. This has often led to the withdrawal of qualified faculty mentors who, if BUILD PODER students were not assigned to them, may not have had the funding required to continue their research. The challenges of conducting research at a community college due to a lack of funds or resources such as time, money, and qualified personnel have been documented in other programs (Brothers and Higgins 2008; Hirst et al. 2014). Lapses in funding between students was a frequent barrier for faculty. Once established and furnished with BUILD PODER students, laboratories could be supported with supplies and small stipends. Despite this support, faculty who invested heavily in their research labs and did not subsequently secure a BUILD PODER student had their work interrupted, a discouraging situation that led many mentors to leave the program.

The lack of access to a readily available IRB committee and procedure at the community college level also has posed significant challenges to students and their faculty mentors in social and behavioral sciences. This often disrupts the student's experience and hinders the mentormentee pair from recruiting participants and proceeding with the data analysis and presentation of their research. Although they can utilize the IRB at the university partner institution, the mechanism is often cumbersome, and delays have meant that some projects could not start quickly enough to provide students with a comprehensive research experience.

The ability for a community college to design and implement an undergraduate research program that is scalable and sustainable depends on a funding source, administrative support, and partnerships with universities or industry. Administrative support is especially essential. Relying on faculty mentors who are simultaneously developing a research program to act in an administrative role in the partnership overburdens faculty. Ideally, the institution can commit to assigning a nonteaching staff member to manage day-to-day operations, freeing time for faculty to focus on research and mentoring. Grant writers should note that, in addition to allocating funding for a faculty liaison, each campus requires a financial and logistics coordinator because of the heavy workload in these areas, at least in the first year.

PCC has developed an effective faculty-administration partnership, in which the dean of natural sciences takes an active role in the organization of research activities. The Early Career Undergraduate Research Experience originated at an NSF undergraduate research workshop attended by faculty and the dean from PCC. This partnership provided a way to grow the program that included construction of an undergraduate research laboratory dedicated to student research projects. Active engagement in the undergraduate research program by administration optimizes the undergraduate research opportunities at a community college.

Challenges overcome. The challenges of scaling a community college undergraduate research program can be mitigated through partnership with and support from a baccalaureate-granting university. A community college instructor's main responsibility is teaching. which can inhibit development of new research or ongoing learning about current research. The partnership with BUILD PODER provides access to research scientists active in their fields, opening research experiences for community college students. For example, the PCC research program applied for and was awarded an NIH pilot program grant in collaboration with a CSUN instructor to design and study energy transfer between gold nanoparticles and antibodies. This partnership allowed PCC students access to an advanced femtosecond pulse laser and funds to buy the reagents and supplies needed for the project.

$$
\text { Spring } 2021 \text { | Volume } 4 \text { | Number } 3 \text { | } 55
$$


Serving as a faculty mentor for the BUILD PODER program does require additional work. Funding should not be the sole issue considered for participation in undergraduate research, but access to compensation as well as travel and supply funds can increase motivation for BUILD PODER mentors, especially when a teaching workload seems overwhelming. Obtaining funding for undergraduate research programs without university partnerships and experience will not happen at most community colleges. Even in the absence of lab space or equipment and limited financial resources, there are still opportunities for students to learn. Even if it requires creativity about projects or the application of survey-based methodology, students can still obtain a full research experience at the community college level.

There may be concern that students and faculty will feel isolated or marginalized working so much on their own projects, but that has not been the experience. Students have the opportunity to collaborate with other labs, present at conferences, and share the work they are doing with others such as friends and family. In addition, the singular relationship between the students and their mentors is meant to feel like an equal partnership, allowing students to oversee and lead all aspects of the research process.

\section{Recommendations}

Based on the perceived challenges, recommendations were made that emphasized the following ideals for those wishing to build a similar program and partnerships: maintaining communication, establishing trust and common goals, and developing a plan specific to each partner institution. For example, during the preparatory phase, program developers should understand that each community college has a distinct culture and therefore must enlist local administration support for creating a research partnership. During this exploratory phase, it also is important to have transparent and goal-oriented conversations with the administration to establish shared goals and missions, develop a timeline, and assign a division of work. This early stage is an opportunity to learn about one another, develop a shared language, and set objectives for the partnership (Asimow, Kennedy, and Lees 2016). This is particularly important for partnerships between community colleges and university research institutions, given the differences in schedules, expectations, demographics, structures, and cultures.

It is unlikely that community college faculty will receive reassigned time or extra pay to establish an undergraduate research program. Therefore, it is the obligation of the faculty member to search out and find networks and programs with dedicated resources for research. Faculty can contact organizations such as the Community College Undergraduate Research Initiative (CCURI); participate in organizational meetings sponsored by the Council on Undergraduate Research (CUR); and identify potential collaborative partners at nearby universities, nonprofit laboratories, and industries. Many federal grants prioritize programs that work with community colleges. Finally, faculty should be willing to prepare grant proposals to fund their research programs. PCC began eCURE with three faculty, 12 PCC STEM students, and a small amount of funding from a Department of Education Title III Strengthening Institutions Program grant. With guidance from a workshop on community college undergraduate research, eCURE was developed as a tiered research approach. Over time eCURE fostered various partnerships to help the program grow such as CSUN's BUILD PODER. It took three years for the eCURE program to begin to show results. After eight years of eCURE at PCC and collaborations with CSUN's BUILD PODER and several other university and industry partners, the program has been awarded an NSF Advanced Technological Education (ATE) pilot program grant and will be the lead institution for the NSF ATE Micro Nano Technology Education Center. Although time, effort, and persistence are required, this new designation of an educational center at PCC shows that institutionalization of research at a community college is possible.

\section{Conclusion}

The BUILD PODER partnership of CSUN and several local community colleges has had several benefits for students and faculty who, in turn, have played a part in developing scientific research cultures across all institutions. Critical race theory is infused in BUILD PODER activities and highlights the importance of recognizing cultural strengths and needs across institutions, leveraging the strengths of community college environments and challenging dominant ideologies about science in the community college context as a tool for recruitment. Overall, to be effective, program developers must understand institutional cultures, discuss shared goals and expectations, provide continued support and workshops to expand research awareness, and maintain communication with stakeholders.

The student results show a stronger science identity and passion for research as a result of collaborative research experiences, enabling the continuation of research opportunities after transfer. The analysis of narratives is qualitative and meant to represent the lessons learned from a small sample of participants of one program in the unique higher education context of southern California. Despite limitations, the results highlight how partnerships between a baccalaureate-granting university and community colleges have the capacity to foster interest in undergraduate research, with a focus on BIPOC students, to promote transfer, and to cultivate diverse perspectives in research.

The power of undergraduate research lies in the connections formed via mentorship that can have a significant impact on a student's academic journey. Community 
college-university partnerships provide this important path. As one student wrote:

My community college mentor was someone that inspired me to pursue a degree in Biochemistry. When I initially paired up with my mentor through BUILD PODER, I was a Nutrition/Dietetics major, and after much discussion with my mentor, not only did I become aware of the opportunities in pursuing a chemically based degree, but I decided I wanted to become a researcher. I recently graduated from CSU Northridge with a B.S. in Biochemistry and this fall I will attend the University of California, Irvine to pursue a Ph.D. in Chemistry. Without my community college mentor that I was paired up with through the BUILD PODER program, I am certain none of this would have been possible.

\section{Acknowledgments}

The BUILDPODER program is funded by the National Institutes of Health grants RL5GM118975 and TL4GM118977, and National Science Foundation Advanced Technological Education grants NSF ATE DUE 1601813 and 2000281. The authors acknowledge and thank the following community college students in BUILD PODER: Cristina Alarcon, Mary Antikyan, Esteban Bautista, Isabel Bojanini, Melanie Hacopian, Sasha Machulsky, David Ohana, Kelly Rodriguez, and Tadeo Zuniga.

\section{References}

Ashcroft, Jared, Veronica Jaramillo, and Jillian Blatti. 2020. "Early Career Undergraduate Research as a Meaningful Academic Experience in which Students Gain Professional Workforce Skills: A Community College Perspective." In Integrating Professional Skills into Undergraduate Chemistry Curricula, ACS Symposium Series, ed. Kelly Y. Neiles, Pamela S. Mertz, and Justin Fair, vol. 1365, 281-299. Washington, DC: American Chemical Society. doi: 10.1021/bk-2020-1365.ch016

Asimow, Jennifer G., Adam S. Kennedy, and Anna T. Lees. 2016. "Beginning with Yes: Reframing the Narrative to Support Community College Transfer Students in Early Childhood Education." In Voices from the Field: Collaborative Innovations in Early Childhood Education Preparation, ed. Stephanie A. Bernoteit, Johnna C. Darragh Ernst, and Nancy I. Latham, 27-46. Springfield: Illinois Education Research Council and Illinois Board of Higher Education.

Bowman, Nicholas A., and Joshua M. Holmes. 2018. "Getting Off to a Good Start? First-Year Undergraduate Research Experiences and Student Outcomes." Higher Education 76: 17-33. doi: 10.1007/s10734-017-0191-4

Brothers, Morina, and Thomas Higgins. 2008. "Research Models that Engage Community College Students." CUR Quarterly 29(1): 12-17.

California Community Colleges (CCCCO). n.d. "Management Information Systems Data Mart.” Accessed April 4, 2021. https:// datamart.cccco.edu/students/enrollment_status.aspx

California Community Colleges (CCCCO). 2020. "Student Rightto-Know Rate Disclosure Website." http://srtk.cccco.edu/index.asp
Carpi, Anthony, Darcy M. Ronan, Heather M. Falconer, and Nathan H. Lents. 2016. "Cultivating Minority Scientists: Undergraduate Research Increases Self-Efficacy and Career Ambitions for Underrepresented Students in STEM." Journal of Research in Science Teaching 54: 169-194. doi: 10.1002/tea.21341

Cejda, Brent D., and Nancy Hensel (Eds.). 2009. Undergraduate Research at Community Colleges. Washington, DC: Council on Undergraduate Research. https://www.cur.org/assets/1/7/Undergraduate_Research_at_Community_Colleges_-_Full_Text_-_ Final.pdf

Chen, Grace. 2019. "Are Community Colleges Becoming the New Leader in STEM Education?" Community College Review. Accessed July 10, 2020. https://web.archive.org/ web/20210117190107/https://www.communitycollegereview. $\mathrm{com} / \mathrm{blog} /$ are-community-college-becoming-the-new-leader-instem-education

Community College Research Center (CCRC). n.d. "Community College FAQs." Teachers College, Columbia University. Accessed July 10, 2020. https://ccrc.tc.columbia.edu/Community-College-FAQs.html

Corbin, Juliet, and Anselm Strauss. 1990. "Grounded Theory Research: Procedures, Canons, and Evaluative Criteria." Qualitative Sociology 13: 3-21. doi: 10.1007/bf00988593

Hernandez, Paul R., Anna Woodcock, Mica Estrada, and P. Wesley Schultz. 2018. "Undergraduate Research Experiences Broaden Diversity in the Scientific Workforce." BioScience 68: 204-211. doi: 10.1093/biosci/bix 163

Hewlett, James A. 2018. "Broadening Participation in Undergraduate Research Experiences (UREs): The Expanding Role of the Community College." CBE-Life Sciences Education 17(3): 1-3. doi: 10.1187/cbe.17-11-0238

Hirst, Rachel A., Gilles Bolduc, Louis Liotta, and Becky WaiLing Packard. 2014. "Cultivating the STEM Transfer Pathway and Capacity for Research: A Partnership between a Community College and a 4-Year College." Journal of College Science Teaching 43(4): 12-17.

Jain, Dimpal, Santiago N. Bernal Melendez, and Alfred R. Herrera. 2020. Power to the Transfer: Critical Race Theory and a Transfer Culture. Perspectives on Access, Equity, and Diversifying Pathways in P-20 Education Series. East Lansing: Michigan State University Press. doi: 10.14321/j.ctvs09qkh

Laungani, Ramesh, Colby Tanner, Tessa Durham Brooks, Barbara Clement, Melissa Clouse, Erin Doyle, Scott Dworak, et al. 2018. "Finding Some Good in an Invasive Species: Introduction and Assessment of a Novel CURE to Improve Experimental Design in Undergraduate Biology Classrooms." Journal of Microbiology and Biology Education 19(2). doi: 10.1128/jmbe. v19i2.1517

Ledesma, Maria C., and Dolores Calderón. 2015. "Critical Race Theory in Education: A Review of Past Literature and a Look to the Future." Qualitative Inquiry 21: 206-222. doi: $10.1177 / 1077800414557825$

Morales-Doyle, D. 2017. "Students as Curriculum Critics: Standpoints with Respect to Relevance, Goals and Science." Journal of Research in Science Teaching 55: 749-773. doi: 10.1002/ tea. 21438 
National Science Foundation (NSF). n.d. "National Science Foundation's Diversity and Inclusion Strategic Plan 2012-2016: In Support of the Government-Wide Effort to Enhance Diversity and Inclusion in the Federal Workforce." Accessed July 10, 2020. https://www.nsf.gov/od/odi/reports/StrategicPlan.pdf

Reeves, Nick Lee, Ana Maria Barral, Karim A. Sharif, Michael J. Wolyniak, Wilson Leung, Chris D. Shaffer, David Lopatto, et al. 2016. "Partnership: Assessing and Improving a Course-Based Undergraduate Research Experience (CURE)." FASEB Journal 30(1): supplement, lb197.

Saetermoe, Carrie L., Gabriela Chavira, Crist S. Khachikian, David Boynes, and Beverly Cabello. 2017. "Critical Race Theory as a Bridge in Science Training: The California State University, Northridge BUILD PODER Program." BMC Proceedings 11: art. 21. doi: 10.1186/s12919-017-0089-2

Sólorzano, Daniel G., Octavio Villalpando, and Leticia Oseguera. 2005. "Educational Inequities and Latina/o Undergraduate Students in the United States: A Critical Race Analysis of Their Educational Progress." Journal of Hispanic Higher Education 4: 272-294. doi: 10.1177/1538192705276550

Steele, Claude M., Steven J. Spencer, and Joshua Aronson. 2002. "Contending with Group Image: The Psychology of Stereotype and Social Identity Threat." Advances in Experimental Social Psychology 34: 379-440. doi: 10.1016/s0065-2601(02)80009-0

Valantine, Hannah A., P. Kay Lund, and Alison E. Gammie. 2016. "From the NIH: A Systems Approach to Increasing the Diversity of the Biomedical Research Workforce." CBE-Life Sciences Education 15(3): 1-5. doi: 10.1187/cbe.16-03-0138

Vasquez-Salgado, Yolanda,Patricia M. Greenfield, and Rocio Burgos-Cienfuegos. 2015. "Exploring Home-School Value Conflicts: Implications for Academic Achievement and Well Being Among Latino First-Generation College Students." Journal of Adolescent Research 30: 271-305. doi: 10.1177/0743558414561297

Villasenor, Veronica, Amber Bui, Angie Shu-Sha Guan, Dimpal Jain, Carrie Saetermoe, Gabriela Chavira, and Crist Khachikian. Manuscript in preparation. "A Whole New Support System: Community College Student Development in a Biomedical Research Training Program Informed by Critical Race Theory (CRT)."

\section{Jared Ashcroft}

Pasadena City College, jmashcroft@ pasadena.edu

Jared Ashcroft, Veronica Jaramillo, and Jillian Blatti are chemistry faculty mentors at PCC. They have mentored community college students through BUILD PODER and the Early Career Undergraduate Research Experience (eCURE) program. Jaramillo and Ashcroft are the lead principal investigators for National Science Foundation Advanced Technological Education grants.

Carrie Saetermoe, Gabriela Chavira, Shu-Sha Angie Guan, Alina Adamian, Amber Bui, and Veronica Villasenor coordinate BUILD PODER at CSUN.

Eileen Ie and Bryant Horowitz are sociology and psychology faculty mentors at ELAC, where Brissa Palacios is a specially funded program specialist. Horowitz also teaches Introduction to Psychology and biological psychology in the ELAC honors program and is a faculty adviser for Psi Beta, a national psychology honors club, as well as for the individual chapter at ELAC that he founded in 2017. Ie has served as a faculty liaison and mentor for BUILD PODER since 2014. She teaches courses such as Human Sexuality, Research Methods, and Race and Ethnicity in the ELAC Honors Program. She cofounded the Delloro Transfer Program in Social Justice in 2014. Ie currently serves as vice chair of sociology and cochair of the Sexual Assault Awareness Violence Education team and is one of the equity leads at ELAC.

Jennifer Moses is a psychology and statistics faculty mentor at LAPC. She also serves as the BUILD PODER liaison between CSUN and LAPC and has mentored community college students through BUILD PODER.

Pamela Byrd Williams and Erika Brockman have served as biology and anatomy faculty mentors for the past seven years in BUILD PODER at LAVC and provided BUILD PODER students with research opportunities. 